\title{
Coalworkers' simple pneumoconiosis and exposure to dust at 10 British coalmines
}

\author{
J F HURLEY, J BURNS,* LIZ COPLAND, J DODGSON, AND M JACOBSEN \\ From the Institute of Occupational Medicine, Edinburgh EH8 9SU, UK
}

ABSTRACT Five physicians' radiological assessments of coalworkers' simple pneumoconiosis (CWP) in 2600 coalminers at 10 British collieries have been studied in relation to the individuals' estimated lifetime (mean 33 years) exposure to respirable coalmine dust. Estimates of exposure were based on 20 years of observations at each colliery. Radiographic classifications were clearly associated with the measures of dust exposure. Important unexplained differences between some of the collieries were disclosed. Among men with similar cumulative dust exposures those with longer exposure time had higher prevalence of CWP. In general there was no evidence that the quartz concentrations experienced (average $5 \%$ of mixed dust) affected the probability of developing coalworkers' simple pneumoconiosis. Some men reacted unfavourably (two or more steps of change on the 12-point radiological scale) over a 10 -year period to coalmine dust with a relatively high quartz content.

Earlier reports from the National Coal Board's Pneumoconiosis Field Research have described an association between exposure to respirable coalmine dust and incidence of coalworkers' simple pneumoconiosis (CWP). ${ }^{1-5}$ The effect of quartz has also been studied. ${ }^{6}$ These were interim investigations, based on a 10-year period of observations of coalface workers at 20 British collieries. Results from a longer-term study at 10 collieries are presented in this paper, which has two main objectives. The first is to report new dust-related estimates of long-term incidence risks of pneumoconiosis among working miners. The second is to present further information on how the chances of developing CWP are influenced by the quartz content of the coalmine dust to which men are exposed.

\section{Subjects}

Since 1953 medical surveys of the Pneumoconiosis Field Research have been carried out at roughly five-year intervals at selected collieries from all the major British coalfields. Ten collieries were surveyed at least five times. They cover a wide range of environmental and geological conditions. All currently employed miners were asked to take part on each occasion. This report considers primarily the 2600 men who attended the first, third, and fifth surveys at the 10 collieries, and for whom complete *Present address: National Coal Board, London SW1X 7AE. Received 13 September 1980 Accepted 11 June 1981 and reliable data were available. Men no longer in the industry were not studied: 8394 men, examined at these collieries at the first surveys, were alive and under 65 years old 20 years later. The 2600 long-term working miners studied form $31 \%$ of that group. Some results are reported for a further 1730 men who attended the third and fifth surveys, but not the first, at these same collieries.

\section{Methods}

\section{RADIOLOGICAL DATA}

Each of five physicians experienced in the radiology of pneumoconiosis classified the fifth survey fullsized (posteroanterior) chest radiographs of the men separately, independently, and in random order according to the ILO U/C International Classification of Radiographs of the Pneumoconioses, ${ }^{7}$ using 1968 standard films. Additionally, the readers classified all 4330 pairs of the third and fifth survey films sideby-side on the viewing box.

OCCUPATIONAL HISTORIES

Throughout the 20 years of observations the mining population within a colliery was divided into occupational groups based on place of work and occupation. A weekly record was kept of the number of hours worked, including overtime, by each man in these groups. Details of the men's other coalmining work were obtained at interviews during the five-yearly surveys and were summarised as years and months worked in six broad classes of coalmining activity. 
One year's work was taken as equivalent to 1740 working hours.

ENVIRONMENTAL MEASUREMENTS

Dust samples were taken close to the men at their places of work and during travelling time underground, and average concentrations of the respirable fractions were calculated for each occupational group. The standard thermal precipitator ${ }^{8}$ was used during the first ten-year period. The MRE gravimetric sampler ${ }^{9}$ was used subsequently, and the environmental sampling programme was intensified. The earlier measurements were converted to equivalent respirable gravimetric values using experimental results of side-by-side instrument comparisons under various mining conditions. ${ }^{10}$ The mineral composition of dust samples from the first 10 years was reassessed recently using a micro-infrared technique ${ }^{11}$ to give percentages of ash, quartz, and kaolin-plusmica in the airborne dust. Corresponding values for the second 10 years were established routinely by ashing and infrared spectroscopy. ${ }^{12}$ Average concentrations of mixed dust and its components over the two ten-year periods were calculated for each of the six major classes of coalmining activity within a colliery. These values were used to estimate the dust concentrations experienced before the project started, and the concentrations at collieries not included in the research during periods when men in the study worked there.

\section{INDIVIDUALS' DUST EXPOSURES}

The sum of products, $\Sigma$ (hours worked in occupational group $x$ average dust concentration in occupational group) was taken as a measure of an individual's exposure to respirable mixed dust at the research colliery over 20 years. Exposures to ash, quartz, and kaolin-plus-mica during this period were obtained similarly. The men's other exposure to coalmine dust and its mineral components was estimated from the occupational histories given at interview and average dust concentrations in the six broad coalmining categories. Thus estimates of cumulative exposures up to the fifth survey were available for each man. The exposure units are gram-hours per cubic metre of sampled air $\left(\mathrm{gh} / \mathrm{m}^{3}\right)$.

An individual's cumulative dust exposures were divided by his total number of working hours to give a measure of the average dust concentrations experienced by the man. The concentration units are milligram per cubic metre of sampled air $\left(\mathrm{mg} / \mathrm{m}^{3}\right)$.

\section{EPIDEMIOLOGICAL APPROACH AND} STATISTICAL METHODS

Two approaches were used. A cross-sectional study was made of the prevalence of CWP among 2600 working miners, 20 years after their initial participation in the research, in relation to estimates of individuals' dust exposures, time worked, and other characteristics. Radiological classifications on the 12-point scale of simple pneumoconiosis were summarised as prevalence of category $2 / 1$ or more CWP, category $0 / 1$ or more, and pneumoconiosis scores. ${ }^{13}$ Secondly, a longitudinal analysis of 4330 men who attended the third and fifth medical surveys was used to generate a pair-matched case-control study of radiological changes. Extensive use was made of cross-tabulations, graphical methods, and summary statistics in describing the many variables and their inter-relations. The relationship of exposure to effect in the cross-sectional study was examined by multiple logistic analyses ${ }^{14}$ of the binary responses, with the associated resources of estimation and significance testing. Conventional parametric tests of differences were used in the case-control study.

\section{Results}

CHARACTERISTICS OF THE MEN STUDIED

The 2600 men were aged from 35 to 65 years at the fifth medical survey (mean 52.1, SD 7.3). All had entered the industry at least 20 years earlier (average 33) and so were not typical of coalminers generally. The mean cumulative dust exposure was $183 \mathrm{gh} / \mathrm{m}^{3}$. Several men had relatively high values; $366(14 \%)$ had exposures greater than $300 \mathrm{gh} / \mathrm{m}^{3}$. Despite differences in average dust concentrations among the 10 collieries, eight included some men in this higher exposed group. On average, $60 \%$ of the men's estimated lifetime exposure was accumulated at the research collieries over the 20 -year study periods, when the data are most reliable. The mean cumulative quartz exposure was $8.8 \mathrm{gh} / \mathrm{m}^{3}$ (SD $5.8 \mathrm{gh} / \mathrm{m}^{3}$ ), corresponding to $5 \%$ (SD $1.9 \%$ ) quartz in mixed dust, on average. Colliery-related differences in quartz concentrations were also evident. Cumulative exposure to quartz was highly correlated $(r=0.77)$ with exposure to mixed dust overall.

\section{SIMPLE PNEUMOCONIOSIS AND MIXED RESPIRABLE DUST}

On average, the five physicians recorded category $0 / 1$ or more CWP at the fifth survey in $13.5 \%$ of the men using the independent randomised reading method, and in $13.0 \%$ using the paired side-by-side method. Corresponding figures for category $2 / 1$ or more were $3.1 \%$ and $2.8 \%$ respectively, and so pneumoconiosis was more prevalent than among British coalminers generally. ${ }^{15}$

Each physician's assessments of the profusion of small rounded opacities in the 2600 men were clearly related to mixed dust exposure. This is illustrated 


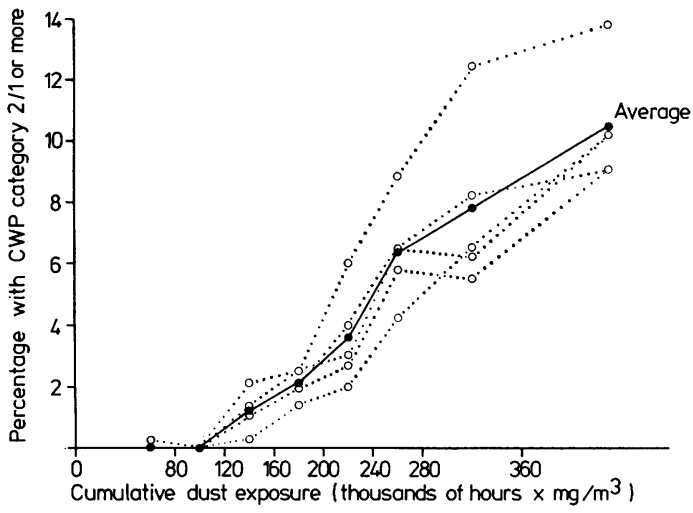

Fig 1 Five readers' separate (independent-randomised) classification of radiographs of 2600 coalminers and average classification, by mean cumulative exposures to mixed respirable coalmine dust from entry to coal mining to time of radiological survey; grouped data.

(fig 1) for prevalence of category $2 / 1$ or more CWP on the 12-point ILO scale, and using the independent randomised reading method. Similar results were obtained using the corresponding side-by-side classifications. Both reading methods also showed an exposure-effect relationship when the radiological data were summarised as prevalence of category $0 / 1$ or more CWP, or as pneumoconiosis scores. The presentation in this paper refers mainly to the average of the five physicians' independent-randomised assessments of category $2 / 1$ or more CWP. Similar results were obtained using the other radiological data.

Table 1 shows that the overall exposure-effect relationship was evident also within individual collieries, but at two of them (T and $Q$ ) there were pronounced differences from the average pattern. Variations between the other eight collieries were relatively small.

In general, among men with similar cumulative dust exposures, those who had worked longer hours in coalmining had higher prevalence of CWP (table 2). No additional age-effect was observed. Table 2 confirms that information on time worked and on dust concentrations are both necessary to describe the risks of CWP.

The fifth survey prevalence of CWP in relation to dust concentrations, time worked, and colliery may be interpreted to give dust and colliery specific estimates of incidence of category $2 / 1$ or more CWP in a survivor population over different periods. One such representation is given in the appendix, and

Table 1 Number of men studied, and (in parentheses) percentage classified* as category $2 / 1$ or more CWP, by colliery

\begin{tabular}{|c|c|c|c|c|c|c|c|c|c|}
\hline \multirow[t]{2}{*}{ Colliery } & \multicolumn{9}{|c|}{ Cumulative dust exposure $\left(\mathrm{gh} / \mathrm{m}^{3}\right)$} \\
\hline & $\leqslant 79$ & 80.119 & $120-159$ & $160-199$ & $200-239$ & $240-279$ & $280-359$ & $\geqslant 360$ & All \\
\hline $\begin{array}{l}\text { C } \\
\text { F } \\
\text { K } \\
\mathbf{P} \\
\mathbf{Q} \\
\text { T } \\
\text { V } \\
\text { W } \\
\text { X } \\
\text { Y } \\
\text { All }\end{array}$ & $\begin{array}{c}42(0) \\
17(0) \\
70(0 \cdot 3) \\
106(0) \\
39(0) \\
34(0) \\
44(0) \\
38(0) \\
37(0) \\
54(0) \\
481(0 \cdot 0)\end{array}$ & $\begin{array}{r}53(0) \\
5(0) \\
53(0) \\
82(0) \\
23(0) \\
24(0) \\
32(0) \\
30(0) \\
18(0) \\
54(0) \\
374(0)\end{array}$ & $\begin{array}{c}70(0 \cdot 3) \\
5(0) \\
61(1 \cdot 6) \\
16(0) \\
26(0) \\
28(12 \cdot 1) \\
38(0) \\
20(0) \\
46(0) \\
62(0) \\
372(1 \cdot 2)\end{array}$ & $\begin{array}{l}44(2 \cdot 3) \\
16(0) \\
44(2 \cdot 3) \\
1(0) \\
33(0) \\
19(10 \cdot 5) \\
43(3 \cdot 3) \\
16(0) \\
64(3 \cdot 1) \\
75(0) \\
355(2 \cdot 1)\end{array}$ & $\begin{array}{c}45(0 \cdot 4) \\
19(21 \cdot 1) \\
34(1 \cdot 8) \\
23(5 \cdot 2) \\
65(2 \cdot 8) \\
56(0) \\
298(3 \cdot 6)\end{array}$ & $\begin{array}{c}1(20 \cdot 0) \\
27(1 \cdot 5) \\
29(1 \cdot 4) \\
\\
36(0) \\
16(42 \cdot 5) \\
43(2 \cdot 8) \\
15(10 \cdot 7) \\
36(6 \cdot 1) \\
58(6 \cdot 6) \\
261(6 \cdot 4)\end{array}$ & $\begin{array}{l}37(7 \cdot 6) \\
11(10 \cdot 9) \\
\\
70(0 \cdot 6) \\
20(30 \cdot 0) \\
68(5 \cdot 6) \\
18(14 \cdot 4) \\
23(15 \cdot 7) \\
44(5 \cdot 0) \\
291(7 \cdot 8)\end{array}$ & $\begin{array}{c}67(16 \cdot 1) \\
1(0) \\
54(3 \cdot 7) \\
1(0) \\
36(11 \cdot 1) \\
2(0) \\
7(8 \cdot 6) \\
168(10 \cdot 4)\end{array}$ & $\begin{array}{l}219(0 \cdot 7) \\
181(7 \cdot 7) \\
309(1 \cdot 7) \\
205(0) \\
326(0 \cdot 8) \\
161(13 \cdot 8) \\
338(3 \cdot 2) \\
162(3 \cdot 3) \\
289(3 \cdot 3) \\
410(1 \cdot 6) \\
2600(3 \cdot 1)\end{array}$ \\
\hline
\end{tabular}

*An average of five readers' independent randomised classifications of fifth survey radiographs.

For each reader's classifications, the number of men with category $2 / 1$ or more CWP in any group was expressed as a percentage of the total number of men studied in that group. Figure in parentheses is an average of these five values.

Table 2 Number of men studied, and (in parentheses) percentage classified* as category 2/1 or more CWP, in relation to dust and time

\begin{tabular}{|c|c|c|c|c|c|c|c|c|c|}
\hline \multirow{2}{*}{$\begin{array}{l}\text { Cumulative hours } \\
\text { worked (in 1000s) }\end{array}$} & \multicolumn{9}{|c|}{ Cumulative dust exposure $\left(\mathrm{gh} / \mathrm{m}^{3}\right)$} \\
\hline & $\leqslant 79$ & $80-119$ & $120-159$ & $160-199$ & $200-239$ & $240-279$ & $280-359$ & $\geqslant 360$ & All \\
\hline $\begin{array}{r}0-39 \\
40-48 \\
49-56 \\
57-64 \\
65-72 \\
73-80 \\
>80 \\
\text { All }\end{array}$ & $\begin{array}{c}73(0) \\
97(0) \\
91(0) \\
70(0) \\
75(0) \\
42(0) \\
33(0 \cdot 6) \\
481(0 \cdot 0)\end{array}$ & $\begin{array}{r}72(0) \\
81(0) \\
65(0) \\
51(0) \\
48(0) \\
35(0) \\
22(0) \\
374(0)\end{array}$ & $\begin{array}{l}84(0) \\
87(2 \cdot 3) \\
68(2 \cdot 4) \\
53(1 \cdot 5) \\
36(0 \cdot 6) \\
29(0) \\
15(0) \\
372(1 \cdot 2)\end{array}$ & $\begin{array}{c}42(0) \\
106(2 \cdot 3) \\
60(0) \\
58(1 \cdot 4) \\
36(6 \cdot 7) \\
35(5 \cdot 1) \\
18(0) \\
355(2 \cdot 1)\end{array}$ & $\begin{array}{c}19(0) \\
45(0 \cdot 9) \\
79(3 \cdot 3) \\
67(3 \cdot 9) \\
42(6 \cdot 2) \\
29(4 \cdot 1) \\
17(7 \cdot 1) \\
298(3 \cdot 6)\end{array}$ & $\begin{array}{c}10(0) \\
26(0) \\
45(2 \cdot 7) \\
81(8 \cdot 9) \\
46(4 \cdot 8) \\
38(13 \cdot 2) \\
15(6 \cdot 7) \\
261(6 \cdot 4)\end{array}$ & $\begin{array}{c}3(0) \\
20(3 \cdot 0) \\
41(1 \cdot 0) \\
64(6 \cdot 3) \\
70(10 \cdot 6) \\
68(11 \cdot 8) \\
25(8 \cdot 8) \\
291(7 \cdot 8)\end{array}$ & $\begin{array}{c}3(0) \\
3(0) \\
7(0) \\
37(11 \cdot 4) \\
33(7 \cdot 3) \\
64(13 \cdot 8) \\
21(9 \cdot 5) \\
168(10 \cdot 4)\end{array}$ & $\begin{array}{c}306(0) \\
465(1 \cdot 2) \\
456(1 \cdot 3) \\
481(4 \cdot 1) \\
386(4 \cdot 5) \\
340(7 \cdot 3) \\
166(4 \cdot 0) \\
2600(3 \cdot 1)\end{array}$ \\
\hline
\end{tabular}

*See table 1. 


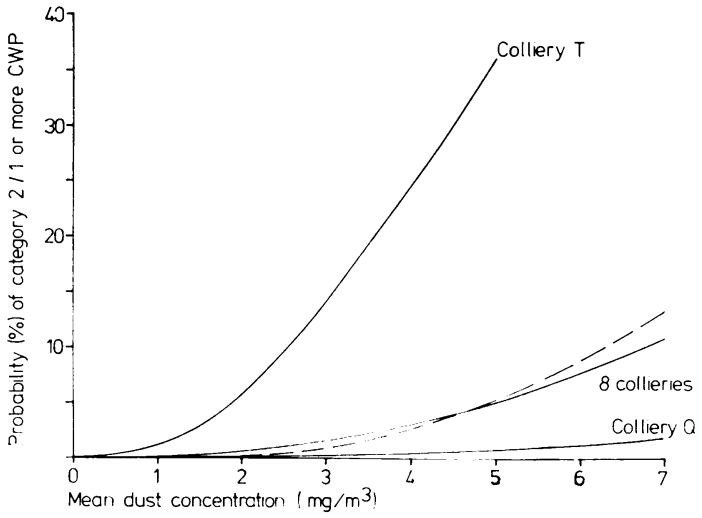

Fig 2 Estimates of probabilities of developing category $2 / 1$ or more simple pneumoconiosis over roughly 35 years.

based on this study: see appendix for
details.
,$\quad \begin{aligned} & \text { based on interim results }{ }^{2} \text { for coalface } \\ & \text { workers only. }\end{aligned}$

illustrated in fig 2 for a period of 60900 working hours. This is close to the average time worked by the 2600 men and approximates to 35 working years, the period used in published estimates from the interim results. ${ }^{2}$ These earlier incidence estimates (fig 2) are similar to the results now from eight collieries. The extreme colliery-related differences in the present study overshadow any differences between the two studies on average.

\section{QUART Z}

There was little evidence that exposures to quartz dust influenced the chances of developing CWP among the 2600 men generally. Representations similar to that of fig 2, but substituting quartz for mixed dust as a variable, did not explain the responses satisfactorily, and there is no pattern in table 3 suggesting a quartz-CWP effect among men with similar exposures to mixed dust. Further, the colliery-related differences were not attributable to quartz. The average quartz content of mixed dust

Table 3 Number of men studied, and (in parentheses) percentage classified* as category 2/1 or more CWP, in relation to dust and quartz exposure

\begin{tabular}{|c|c|c|c|c|c|c|c|c|c|}
\hline \multirow{2}{*}{$\begin{array}{l}\text { Cumulative } \\
\text { quartz exposure } \\
\left(\mathrm{gh} / \mathrm{m}^{3}\right)\end{array}$} & \multicolumn{9}{|c|}{ Cumulative dust exposure $\left(\mathrm{gh} / \mathrm{m}^{3}\right)$} \\
\hline & $\leqslant 79$ & $80-119$ & $120-159$ & $160-199$ & $200-239$ & $240-279$ & $280-359$ & $\geqslant 360$ & All \\
\hline $0-3$ & $385(0 \cdot 1)$ & $108(0)$ & $24(0)$ & $9(4 \cdot 4)$ & & & & & $526(0 \cdot 1)$ \\
\hline 4- 5 & $62(0)$ & $151(0)$ & $120(0)$ & $39(0 \cdot 5)$ & $29(4 \cdot 1)$ & $12(13 \cdot 3)$ & $6(16 \cdot 7)$ & & $419(1 \cdot 0)$ \\
\hline $6-7$ & $25(0)$ & $81(0)$ & $113(1 \cdot 6)$ & $100(1 \cdot 8)$ & $32(4 \cdot 4)$ & $30(2 \cdot 7)$ & $31(3 \cdot 2)$ & $3(0)$ & $415(1 \cdot 6)$ \\
\hline 8- 9 & $9(0)$ & $27(0)$ & $75(2 \cdot 9)$ & $65(1 \cdot 5)$ & $51(0)$ & $47(8 \cdot 1)$ & $40(6 \cdot 0)$ & $22(3 \cdot 6)$ & $336(3.0)$ \\
\hline $10-12$ & & $6(0)$ & $38(1 \cdot 6)$ & $103(3 \cdot 7)$ & $70(6 \cdot 0)$ & $52(11 \cdot 2)$ & $66(13 \cdot 6)$ & $39(16 \cdot 4)$ & $374(8 \cdot 0)$ \\
\hline $13-15$ & & $1(0)$ & $2(0)$ & $37(0)$ & $74(4 \cdot 3)$ & $57(4 \cdot 2)$ & $37(5 \cdot 4)$ & $33(23 \cdot 0)$ & $241(6 \cdot 3)$ \\
\hline $16-19$ & & & & $2(10.0)$ & $41(1 \cdot 5)$ & $56(3.9)$ & $49(7 \cdot 8)$ & $15(4 \cdot 0)$ & $163(4 \cdot 5)$ \\
\hline$>20$ & & & & & $1(0)$ & $7(0)$ & $62(5 \cdot 5)$ & $56(3 \cdot 6)$ & $126(4 \cdot 3)$ \\
\hline All & $481(0 \cdot 0)$ & $374(0)$ & $372(1 \cdot 2)$ & $355(2 \cdot 1)$ & $298(3 \cdot 6)$ & $261(6 \cdot 4)$ & $291(7 \cdot 8)$ & $168(10 \cdot 4)$ & $2600(3 \cdot 1)$ \\
\hline
\end{tabular}

*See table 1.

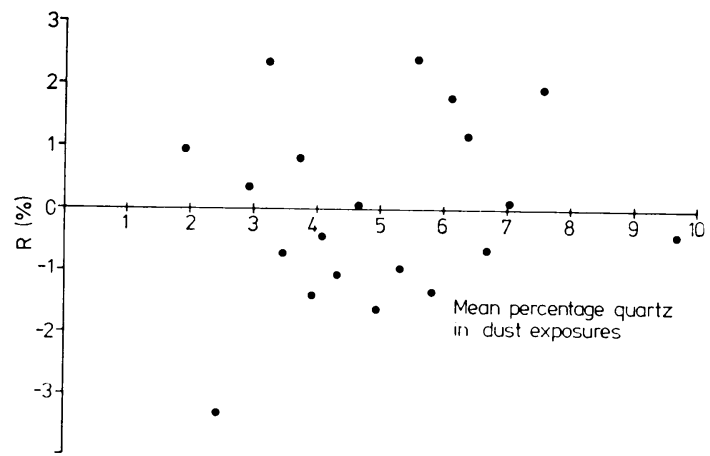

Fig 3 Differences $(R)$ between observed and predicted percentages of men with category 2/1 or more simple pneumoconiosis, by mean percentage quartz in mixed coalmine dust exposure. (Data ranked by percentage quartz; 130 men per group. Observed percentages from average of five readers' independent-randomised classifications. Predicted percentages from equation given in appendix.) exposures at colliery $\mathrm{T}$ was $5.0 \%$, the same as that for all 2600 men. At colliery $Q$ the quartz content was higher $(6.4 \%)$. Finally, representations of the mixed dust-CWP relationship were improved only marginally by considering also the variation in quartz exposures; the classifications of one of the five readers did show a quartz effect additional to that of mixed dust. Brief details are given in the appendix, together with summary results on the choice of mathematical representation used in this study. Figure 3 illustrates the lack of evidence of an overall effect of quartz in the classifications of the readers generally.

There is evidence, however, that some miners show unusual radiological changes when exposed to coalmine dust with a relatively high quartz content. This was determined from the case-control study, using data from 4330 men who had worked at the collieries during the second 10 -year research periods. Forty-five of these miners showed two or more 


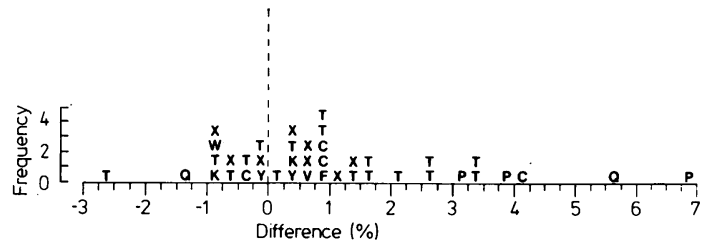

Fig 4 Differences (case-control) in percentage quartz in exposure to mixed coalmine dust over 10 years. (Cases: two or more positive steps of change over 10 years on 12-point radiological scale. (Each letter represents one of the 10 collieries studied.))

positive steps of radiological change on the 12-point scale of simple pneumoconiosis over the 10-year intervals. (This was based on the concurring judgments of at least three of the five film readers, using their side-by-side assessments of the film-pairs concerned.) The same criterion for reader agreement was applied to selected matched controls who showed no positive radiological change over the 10 years. Matching factors were $(a)$ colliery, $(b)$ whether or not the subject was aged over 35 at the start of the 10 -year period, and $(c)$ whether or not the subject's initial radiograph had been classified as higher than category $0 / 0$ at the earlier survey. Subject to these constraints, controls were selected so as to minimise the paired differences between cases and controls in their cumulative exposures to mixed dust up to the end of the 10-year periods. Imposition of these conditions determined that only 41 of the 45 cases were matched with controls, with at least one pair from each of the 10 collieries. Figure 4 summarises the results. It shows an association between the unusual radiological changes and the quartz content of the dust to which the miners were exposed in the 10 -year periods. The mean of the paired differences shown in fig 4 is greater than $1 \%$, and the standardised mean difference ( $t$ ) is 3.5 . A value of $t$ as high as this is very unlikely to arise by chance in the absence of a real association between unusual radiological changes and the quartz content of the dust exposures $(p<0.002)$. The highest single value of quartz in the exposures considered was $20 \%$. Paired differences in percentage quartz experienced over the 10 years were not correlated with corresponding differences in mixed dust exposures.

The possible effects of ash and of kaolin-plus-mica in respirable mixed dust were also examined for the 2600 men. There was no evidence of association with prevalence of simple pneumoconiosis when the effect of respirable mixed dust was taken into account. Nor did the case control study point to any effects of these variables.

Further details of the results reported here are available on request.* These include information on the role of film reading methods, ways of summarising the radiological classifications, colliery differences, selection and goodness-of-fit of the mathematical representation used, quartz, ash, and kaolin-plus-mica exposures, as well as more comprehensive data on cases and controls in the second study.

\section{Discussion}

The radiological signs considered in this report do not necessarily imply clinically significant abnormalities, impairment of lung function, or high mortality. ${ }^{16-18}$ The data are classifications of radiographic appearances using standardised procedures suitable for epidemiological studies ${ }^{7}$; they are not diagnoses of disease or assessments of disability. Risks of developing complicated pneumoconiosis (progressive massive fibrosis), however, are known to be relatively high for miners with category $2 / 1$ or more simple pneumoconiosis. ${ }^{19} 20$ The radiological signs discussed above can therefore be regarded as an indirect measure of increased risks of reduced breathing capacity, disability, and excess mortality.

Important differences occur between the interim studies $^{1-6}$ and the present work-for example, in choice of research collieries, in the criteria for including coalminers in the studies, in the group of physicians who classified the radiographs, and in the methods of film classification. In particular the earlier studies had examined radiological progression over 10 -year periods in relation to respirable mixed dust concentrations measured during those periods. The analyses reported now relate the prevalence of CWP after 20 years of observations to estimates of the individuals' lifetime exposure to respirable mixed dust. Hence it was important to confirm the correlation between radiological signs and measures of dust exposure. The new results do this, and they show additionally that the chances of CWP depend not only on cumulative respirable dust exposure but also on the periods contributing to the exposure estimates. This is consistent with other reports, ${ }^{21}$ and it may reflect an underlying relationship of CWP to residence-time of dust in the lung. We did not study residence-time directly, but used instead a time variable that reflected roughly the number of hours worked as a coalminer.

On average $60 \%$ of the men's lifetime exposure was accumulated during the 20 years of detailed observations at the 10 research collieries. It was necessary to estimate other exposure, and there is evidence that at some collieries dust concentrations *Institute of Occupational Medicine Report No TM/79/13. 
before the research were higher than those of the first 10-year periods. If so our estimates of individuals' earliest exposure to coalmine dust may be low, especially for men with longest working life. Errors of this sort would lead to an overestimate of overall risks, and of the real time-related effect.

There were only small variations between eight of the 10 collieries in the risks associated with working in similar dust conditions for the same length of time. Results for men at the other two collieries differed sharply from this pattern. Mineralogical characteristics of the coal may influence the dustpneumoconiosis relationship. ${ }^{622}$ In this study the colliery differences were associated with various coal rank indices-for instance, percentage carbon (range $81 \cdot 1-94 \cdot 0 \%$ ). This association, however, does not explain the extreme observations at collieries $\mathrm{T}$ and $\mathrm{Q}$. Low risks at colliery $\mathrm{Q}$ had been noted previously, ${ }^{6}$ but very high dust-related risks at colliery $T$ were not expected. One possible contributing factor is that many miners left colliery $\mathrm{T}$ shortly before the fifth medical survey due to the imminent closure of the pit. Thus the 20-year survivor population studied there may be the result of an unusual pattern of selection. There is some evidence that the excess at colliery $\mathrm{T}$ was inflated by an underestimation of the miners' exposures accumulated before the first medical survey. Investigation of these and other possibilities continues.

In the earlier study, results from 10 -year periods of observation were extrapolated to give estimates of incidence risks over 35 working years. This necessitated several assumptions whose plausibility has been discussed elsewhere. ${ }^{5}$ In the present study it was possible to estimate directly, without temporal extrapolation, the incidence risks over 35 years' coalmining work on the assumption that men entering the industry do not show radiological signs, and that CWP category $2 / 1$ or more, once observed, does not regress. Despite these and other major differences between the studies the risks estimated 10 years ago are similar to those reported now at eight collieries. Additionally, a colliery-weighted average of the new estimates over all 2600 men is roughly $1 \%$ probability unit higher than the earlier figures, for dust concentrations in the range $2-4.5 \mathrm{mg} / \mathrm{m}^{3}$. Note that the new mathematical representation (see appendix) admits the possibility of CWP at very low dust exposures, although in practice only one such classification was recorded, by only one reader, among the 855 men with low dust exposures $(<120$ $\left.\mathrm{gh} / \mathrm{m}^{3}\right)$.

It is encouraging that two very different studies should give such similar results on average, and that the new data from eight of the 10 collieries are close to these average figures. Because of this agreement we consider these average risks a reasonable guide to what is likely to be experienced generally by other miners over a working life in similar conditions. There are several reasons, however, why the estimates might be inexact or misleading when applied to other conditions. Firstly, it is clear that at some collieries risks are far lower, or far higher, than the average values. This implies that our probability estimates will not necessarily reflect the risks to coalminers generally (in Britain or elsewhere) unless the dust concentrations and the sources of unexplained colliery-related variability occur in a pattern broadly similar to that observed in this study. Secondly, both studies were based on currently employed men who had presented themselves for medical surveys. This may have led to a preferential inclusion of healthier men. Finally, the radiological and exposure data, though reliable, are not exact. Research on the importance of these various factors is in progress, including a follow-up study of men who have now left the industry.

Earlier studies of British data ${ }^{2} 620$ did not show that quartz in mixed coalmine dust has a clearcut effect on the chances of developing coalworkers' pneumoconiosis. Similar negative findings have been reported from the Ruhr coalfield in Germany. ${ }^{21}$ Our main results again show little evidence of an overall quartz effect for concentrations generally experienced by these miners (average $5 \%$ ), with only one of the five readers detecting an influence. Probably, however, individuals' estimated lifetime exposures to quartz are less accurate than the corresponding mixed dust exposure estimates, and so a slight overall quartz effect might therefore remain hidden. The separate study of unusual radiological changes over 10-year periods points to a real association between these (relatively infrequent) events and exposure to coalmine dust with a high quartz content.

\section{Conclusions}

On average, the new incidence risks estimated from a long-term study of 2600 miners are similar to, but marginally higher than, those reported 10 years ago based on different observations. We consider these average risks a reasonable guide to what is likely to be experienced generally in a survivor population. Nevertheless, extreme colliery-related differences occur for reasons we do not understand. No clearcut overall effect of quartz was found, though some men reacted unfavourably over relatively short (10-year) periods to dust with a relatively high quartz content.

Reliable radiological classifications are essential for studies of this type; we acknowledge gratefully the 
Table 4 Maximised log-likelihood from selected logistic models of probability ( $p$ ) of showing category 2/1 or more $C W P$ among working miners after exposure for $t$ thousand hours to respirable coalmine dust of average concentration $d \mathrm{mg} \mathrm{m}^{-3}$ and quartz concentration $q \mathrm{mg} \mathrm{m} \mathrm{m}^{-3}$. Three constants were included in all five models to reflect differences in relationships at collieries $Q, T$, and the group of eight other pits

\begin{tabular}{|c|c|c|c|c|c|c|}
\hline \multirow[t]{2}{*}{ Model } & \multirow{2}{*}{$\begin{array}{l}\text { Logit }(p)=\text { three constants plus terms as } \\
\text { shown }\end{array}$} & \multicolumn{5}{|l|}{ Reader } \\
\hline & & 03 & 04 & 15 & 17 & 54 \\
\hline $\begin{array}{l}\text { I } \\
\text { II } \\
\text { III } \\
\text { IV } \\
\text { V }\end{array}$ & $\begin{array}{l}a_{4}(d \cdot t) \\
a_{4}[\ln (d . t)] \\
a_{4}[\ln (d)]+a_{5}[\ln (t)] \\
a_{4}[\ln (q)]+a_{5}[\ln (t)] \\
a_{4}[\ln (q)]+a_{5}[\ln (d)]+a_{6}[\ln (t)]\end{array}$ & $\begin{array}{l}-294 \cdot 0 \\
-283 \cdot 4 \\
-277 \cdot 6 \\
-289 \cdot 2 \\
-276 \cdot 9\end{array}$ & $\begin{array}{l}-220 \cdot 0 \\
-211 \cdot 6 \\
-208 \cdot 0 \\
-223 \cdot 4 \\
-207 \cdot 5\end{array}$ & $\begin{array}{l}-375 \cdot 7 \\
-360 \cdot 4 \\
-354 \cdot 3 \\
-380 \cdot 7 \\
-354 \cdot 3\end{array}$ & $\begin{array}{l}-249 \cdot 9 \\
-244 \cdot 2 \\
-242 \cdot 4 \\
-244 \cdot 7 \\
-238 \cdot 4\end{array}$ & $\begin{array}{l}-268 \cdot 3 \\
-260 \cdot 6 \\
-257 \cdot 2 \\
-276 \cdot 7 \\
-257 \cdot 1\end{array}$ \\
\hline
\end{tabular}

help of Drs J G Bennett, J A Dick, D J Thomas, and J S Washington who joined one of us (JB) in reading the films. The work has been financed by the National Coal Board since 1953. We thank the Board, our many past and present colleagues in the research team, and the miners who participated in the surveys.

\section{Appendix}

Separately for the five readers, multiple logistic models were fitted to the radiological responses of category $2 / 1$ or more CWP at the fifth surveys, using ungrouped data for the 2600 men. Fitting was by maximum likelihood methods using NewtonRaphson iteration.

Table 4 summarises results from different ways of representing the effects of exposure. All the formulations allow for some colliery-specific differences. Model I includes a conventional dust exposure term: the product of time and average dust concentration experienced. Working on the log scale (model II) gives for all readers a better representation, consistent with the shape of the relationship (fig 1). The varying influence of exposure depending on time worked (table 2) is reflected in the improvement of model III over model II, as shown by the change in log-likelihoods. (Adding any extra term leads to some increase in the maximised log-likelihood; an irrelevant term would lead to a change of 1.92 units or more, about five times in a hundred). Comparison of models III and IV shows that quartz in place of mixed coalmine dust does not represent the data adequately. Finally (model V), the addition of log quartz concentration to model II does not really help explain the radiological classifications, except for one reader (17) where a clear improvement was found. Note that the differences between readers in maximum log-likelihood achieved reflect differing prevalences of category $2 / 1$ or more CWP recorded.

In view of these results model III was chosen to represent the data. Estimated coefficients for each reader were of similar magnitudes. Averages of these coefficients were used to provide a summary overall relationship for fig 2 , with

$\operatorname{logit}(\mathrm{p})=-24.6028-1.9059(\mathrm{Q})+2 \cdot 3427(\mathrm{~T})$

$$
+2 \cdot 4352[1 \mathrm{n}(\mathrm{d})]+4 \cdot 3222[\ln (\mathrm{t})]
$$

where $p, d$, and $t$ are as in table 4 , while $Q$ and $T$ are dummy variables reflecting differences between these collieries and the group of eight.

\section{References}

1 Jacobsen M, Rae S, Walton WH, Rogan JM. New dust standards for British coal mines. Nature 1970;227:445-7.

2 Jacobsen M, Rae S, Walton WH, Rogan JM. The relation between pneumoconiosis and dust exposure in British coal mines. In: Walton WH, ed. Inhaled particles III. Old Woking (Surrey): Unwin Bros, 1971:903-19.

3 Jacobsen M. The basis for the new coal dust standards. The Mining Engineer 1972;131:269-79.

' Jacobsen M. Progression of coalworkers' pneumoconiosis in Britain in relation to environmental conditions underground. In: Proceedings of the conference on technical measures of dust prevention and suppression in mines, Luxembourg 1972. Luxembourg: Commission of the European Communities, 1973:77-93.

5 Jacobsen M. Effects of some approximations in analyses of radiological response to coalmine dust exposure. In: Recent advances in the assessment of the health effects of environmental pollution. Vol 1. Luxembourg: Commission of the European Communities, 1975:211-29.

${ }^{6}$ Walton WH, Dodgson J, Hadden GG, Jacobsen M. The effect of quartz and other non-coal dusts in coalworkers' pneumoconiosis. In: Walton WH, ed. Inhaled particles IV. Oxford: Pergamon Press, 1977:669-90.

${ }^{7}$ International Labour Office. ILO U/C International classification of radiographs of pneumoconioses, 1971. Geneva: ILO, 1972. (Occupational Safety and Health Series No 22.)

8 Watson HH. The thermal precipitator. Transactions of the Institution of Mining and Metallurgy 1936-7;46:155-240.

${ }^{9}$ Dunmore JH, Hamilton RJ, Smith DSG. An instrument for the sampling of respirable dust for subsequent gravimetric assessment. Journal of Scientific Instruments 1964;41:669-72.

${ }^{10}$ Dodgson J, Hadden GG, Jones CO, Walton WH. Characteristics of the airborne dust in British coalmines. In: Walton WH, ed. Inhaled particles III. Old Woking (Surrey): Unwin Bros, 1971;757-81.

${ }^{11}$ Dodgson J, Cowie AJ, Paris I, Whittaker W. A study of the importance of dust composition in relation to pneumoconiosis in coalminers. Final report on CEC Contract 6253-32/8/018. Edinburgh: Institute of Occupational Medicine, 1977. (IOM Report TM/77/8.) 
${ }^{12}$ Dodgson J, Whittaker W. The determination of quartz in respirable dust samples by infrared spectrophotometry, I. Ann Occup Hyg 1973;16:373-87.

${ }^{13}$ Liddell FKD, Lindars DC. An elaboration of the ILO classification of simple pneumoconiosis. $\mathrm{Br} \mathrm{J}$ Ind Med $1969 ; 26: 89-100$.

${ }^{14}$ Cox DR. The analysis of binary data. London: Methuen, 1970.

${ }^{15}$ National Coal Board. Medical Service Annual Report 1978-79. London: NCB (Medical Service), 1980.

${ }^{16}$ Rogan JM, Attfield MD, Jacobsen M, Rae S, Walker DD Walton WH. Role of dust in the working environment in development of chronic bronchitis in British coal miners. Br J Ind Med 1973;30:217-26.

17 Cochrane AL, Haley TJL, Moore F, Hole D. The mortality of men in the Rhondda Fach, 1950-1970. Br J Ind Med
1979;36:15-22.

18 Jacobsen M. Dust exposure, lung diseases and coalminers' mortality. University of Edinburgh, 1976. (PhD Thesis.)

19 Cochrane AL. The attack rate of progressive massive fibrosis. Br J Ind Med 1962;19:52-64.

${ }^{20}$ McLintock JS, Rae S, Jacobsen M. The attack rate of progressive massive fibrosis in British coalminers. In: Walton $\mathrm{WH}$, ed. Inhaled particles III. Old Woking (Surrey): Unwin Bros, 1971 :933-52.

${ }^{21}$ Reisner MTR. Erkenntnisse epidemiologischer Untersuchungen für den Schutz vor Stauberkrankungen. Gluckauf 1977;113:21-6.

${ }^{22}$ Bennett JG, Dick JA, Kaplan YS, et al. The relationship between coal rank and the prevalence of pneumoconiosis. Br J Ind Med 1979;36:206-10. 